\title{
Cisplatin regulates cell autophagy in endometrial cancer cells via the PI3K/AKT/mTOR signalling pathway
}

\author{
QIONGYAN LIN ${ }^{1,2}$, YIFENG WANG ${ }^{1}$, DUNJIN CHEN $^{2}$, XIUJIE SHENG $^{2}$, JUAN LIU $^{2}$ and HANZHEN XIONG ${ }^{2}$ \\ ${ }^{1}$ Department of Gynaecology and Obstetrics, Zhujiang Hospital, Southern Medical University, \\ Guangzhou, Guangdong 510280; ${ }^{2}$ Department of Gynaecology and Obstetrics, The Third Affiliated \\ Hospital of Guangzhou Medical University, Guangzhou, Guangdong 510150, P.R. China
}

Received October 5, 2015; Accepted January 17, 2017

DOI: $10.3892 / \mathrm{ol} .2017 .5894$

\begin{abstract}
Endometrial cancer is the most common gynaecological malignancy encountered in developed countries and the second most common in the developing world. The five-year survival rate of patients with endometrial cancer diagnosed at a late stage is $<30 \%$. Therefore, it is critical to develop a suitable chemotherapeutic regimen for late-stage endometrial cancer. Cisplatin (CDDP) is a first-line chemotherapeutic drug for endometrial cancer chemotherapy. The present study investigated the molecular mechanism underlying the effect of CDDP on endometrial cancer from the perspective of cell autophagy. Ishikawa cells were treated with 10, 20, 40 or $80 \mu \mathrm{g} / \mathrm{ml}$ CDDP for $12,24,48$ and $72 \mathrm{~h}$. The cells were then harvested and subjected to cell proliferation assays. Based on the results, $20 \mu \mathrm{g} / \mathrm{ml}$ CDDP was selected as the treatment used for 12 and $24 \mathrm{~h}$ for the assays. To detect the effect of CDDP on Ishikawa cell autophagy, autophagosome formation was observed using a transmission electron microscope, and the expression level of autophagy-related gene microtubule-associated protein 1 light chain $3 \alpha$, was examined using immunofluorescence microscopy. The results demonstrated that CDDP treatment promoted cell autophagy in Ishikawa cells. In addition, the total and phosphorylated protein levels of phosphoinositide 3-kinase (PI3K) p85, protein kinase $\mathrm{B}$ (AKT) and mammalian target of rapamycin (mTOR), the key proteins of the PI3K/AKT/mTOR signalling pathway, were detected by western blot analysis. The results indicated that CDDP treatment inactivated the PI3K/AKT/mTOR signalling pathway. To further examine whether CDDP affects cell autophagy in Ishikawa cells via the PI3K/AKT/mTOR signalling pathway, the cells were co-treated with a PI3K
\end{abstract}

Correspondence to: Dr Yifeng Wang, Department of Gynaecology and Obstetrics, Zhujiang Hospital, Southern Medical University, 18th Floor, 253 Industrial Avenue, Haizhu, Guangzhou, Guangdong 510280, P.R. China

E-mail:wyf1988@163.com

Key words: endometrial cancer, autophagy, PI3K/AKT/mTOR, cisplatin activator, insulin-like growth factor-1 (IGF-1). The results demonstrated that IGF-1 co-treatment reversed the effect of CDDP on cell autophagy in Ishikawa cells. In brief, the present study hypothesized that CDDP may regulate cell autophagy in the Ishikawa endometrial cancer cell line via the $\mathrm{PI} 3 \mathrm{~K} / \mathrm{AKT} / \mathrm{mTOR}$ signalling pathway.

\section{Introduction}

Endometrial cancer is a cancer of the endometrium (the lining of the uterus), and is a common gynaecologic malignancy encountered in developed countries and the second most common in the developing world (1). The leading treatment method for endometrial cancer is abdominal hysterectomy (total surgical removal of the uterus), along with removal of the fallopian tubes and ovaries on both sides, which is known as a bilateral salpingo-oophorectomy (2). If the disease is diagnosed at an early stage, the outcome is favourable, and the overall five-year survival rate in the United States is $>80 \%$ (3). However, the majority of cases of endometrial cancer are diagnosed at a later stage and the outcome is poor, with a five-year survival rate of $<30 \%$ (3). Therefore, it is critical to develop suitable chemotherapeutic regimens for late-stage endometrial cancer. It is also important to demonstrate the molecular mechanism underlying the effect of chemotherapeutic drugs on endometrial cancer treatment.

Autophagy is a dynamic process involving the rearrangement of subcellular membranes to sequester the cytoplasm and organelles for delivery to the lysosome or vacuole, where the sequestered cargo is degraded and recycled (4). Autophagy has been implicated in the pathogenesis of cancer, and is commonly referred to as a 'double-edged sword' for its role in tumour progression and tumour suppression (5). Previous studies have revealed that chemotherapy drugs may regulate autophagy in the cells of a number of cancer subtypes (6-8). Cisplatin (CDDP) is the first-line chemotherapeutic drug for endometrial cancer chemotherapy (9). CDDP-induced autophagy has been reported in numerous types of cancer cells, including hepatocellular carcinoma (10), laryngeal cancer (11) and lung adenocarcinoma (12), though the association between CDDP and autophagy varied between types of cancer cell. Treatment with CDDP was demonstrated to activate autophagy in hepatocellular carcinoma and lung adenocarcinoma; however, 
it suppressed autophagy in laryngeal cancer (10-12). The present study investigated the association between CDDP and autophagy in endometrial cancer.

The activation of phosphoinositide 3-kinase (PI3K) or mammalian target of rapamycin (mTOR) are two of the most common events in the development of human cancer, including endometrial cancer $(5,13)$. Alteration of the PI3K/protein kinase B (AKT)/mTOR signalling pathway is implicated in endometrial cancer pathogenesis (14). Previous studies have demonstrated that the PI3K/AKT/mTOR signalling pathway may repress autophagy in response to insulin-like and other growth factor signals $(15,16)$. However, it is not clear whether CDDP regulates cell autophagy in endometrial cancer cells by the PI3K/AKT/mTOR signalling pathway. In the present study, it was considered whether CDDP regulated cell autophagy in the endometrial cancer cell line Ishikawa via the $\mathrm{PI} 3 \mathrm{~K} / \mathrm{AKT} / \mathrm{mTOR}$ signalling pathway, a hypothesis that was confirmed by the results.

\section{Materials and methods}

Materials and reagents. The Ishikawa human endometrial cancer cell line was purchased from the American Type Culture Collection (ATCC; Manassas, VA, USA). RPMI-1640 medium, fetal bovine serum (FBS), PBS, sodium pyruvate, trypsin and antibiotics were purchased from HyClone (GE Healthcare Life Sciences, Logan, UT, USA). CellTiter $96^{\circledR}$ AQueous One Solution Cell Proliferation Assay kit was purchased from Promega Corp. (Madison, WI, USA). Polyvinylidene fluoride (PVDF) membrane was purchased from EMD Millipore (Billerica, MA, USA). Molecular weight markers were purchased from Fermentas (Thermo Fisher Scientific, Inc., Pittsburgh, PA, USA). Bicinchoninic acid (BCA) protein assay kit and radioimmunoprecipitation assay (RIPA) buffer were obtained from Beyotime Institute of Biotechnology (Shanghai, China). Freeze-dried CDDP powder was purchased from Qilu Pharmaceutical Co., Ltd. (Jinan, China). Mouse monoclonal anti-PI3K p85 antibody (ab40776), mouse monoclonal anti-AKT1 antibody (ab89402), rabbit polyclonal anti-AKT1 (phospho-S473) antibody (ab66138), rabbit monoclonal anti-mTOR antibody (ab32028), rabbit monoclonal anti-mTOR (phospho-S2448) antibody (ab109268), rabbit polyclonal anti-microtubule-associated protein 1 light chain $3 \alpha$ (LC3) B antibody (ab63817) and rabbit polyclonal anti-GAPDH antibody (ab9485) were all purchased from Abcam (Cambridge, UK). Enhanced chemiluminescence (ECL) reagent was obtained from EMD Millipore. Alexa Fluor 488-conjugated donkey anti-rabbit immunoglobulin (Ig)G secondary antibodies were provided by Santa Cruz Biotechnology, Inc. (Dallas, TX, USA) (sc-3895). Horseradish peroxidase-conjugated goat anti-rabbit $\operatorname{IgG}$ was purchased from Boster Biological Technology (BA1055; Wuhan, China). Insulin-like growth factor-1 (IGF-1) was purchased from Sino Biological, Inc. (Beijing, China).

Cell culture and CDDP treatment. Ishikawa cells were maintained on culture dishes in $90 \%$ (v/v) RPMI-1640 medium supplemented with $2 \mathrm{mM}$ L-glutamine and $1.5 \mathrm{~g} / 1$ sodium bicarbonate with $10 \%(\mathrm{v} / \mathrm{v}) \mathrm{FBS}$. The cells were cultured in an atmosphere containing $5 \% \mathrm{CO}_{2}$ at $37^{\circ} \mathrm{C}$ in an incubator.
A stock solution of CDDP was prepared in dimethyl sulfoxide (DMSO) at $1 \mathrm{mg} / \mathrm{ml}$ and was further diluted to the final working concentrations $(10,20,40$ and $80 \mu \mathrm{g} / \mathrm{ml})$ with antibiotic-free RPMI-1640 medium.

Cell proliferation assays. Cell proliferation was evaluated using the CellTiter $966^{\circledR}$ AQueous One Solution Cell Proliferation Assay kit, according to the manufacturer's protocol. Ishikawa cells $\left(1 \times 10^{4}\right.$ cells) were seeded onto 96 -well plates. Following $4 \mathrm{~h}$ of incubation, $10 \mu \mathrm{l} \mathrm{CDDP}$ in $1 \%$ DMSO was added to the wells at 10,20,40 and $80 \mu \mathrm{g} / \mathrm{ml}$, whereas $10 \mu \mathrm{l} 1 \%$ DMSO was used as the negative control. Briefly, following CDDP treatment for 0, 6, 12, 24 and $48 \mathrm{~h}, 20 \mu \mathrm{l}$ CellTiter $96^{\circledR}$ AQueous One Solution reagents were added to each well and incubated for $4 \mathrm{~h}$ at $37^{\circ} \mathrm{C}$. The absorbance was determined at $490 \mathrm{~nm}$ using a Multiskan MK3 microplate reader (Thermo Fisher Scientific, Inc., Waltham, MA, USA). The experiments were repeated three times, and the rate of cell proliferation inhibition was evaluated using the following formula: Inhibition rate $(\%)=1-($ mean absorbance of treated cells/mean absorbance of the negative control) $\mathrm{x} 100$.

Transmission electron microscopy. The autophagy of Ishikawa cells was evaluated by autophagosome screening under a JEM-1010 transmission electron microscope (Matsunaga Manufacturing, Co., Ltd., Gifu, Japan). At the end of the intervention, the cells were digested with $0.25 \%$ trypsin and collected in centrifuge tubes, followed by centrifugation at $100 \times \mathrm{g}$ for $10 \mathrm{~min}$, then $80 \times \mathrm{g}$ for $10 \mathrm{~min}$, at $4^{\circ} \mathrm{C}$. The supernatant was discarded, and $2.5 \%$ glutaraldehyde was added to the tube to fix the cells. Following a 2-h period of fixation, dehydration, and embedding, ultra-thin sections $(70 \mathrm{~nm})$ were prepared using a microtome and each section was mounted on a copper grid. Samples were contrasted with $4 \%$ aqueous uranyl acetate (10 min) and then Reynolds lead citrate (2 min). The autophagosomes were observed under a transmission electron microscope and imaged.

Western blot analysis. Each group of Ishikawa cells was washed twice with ice-cold PBS, and resuspended in ice-cold RIPA buffer supplemented with $1 \mathrm{mmol} / \mathrm{l}$ phenylmethanesulfonyl fluoride and a cocktail of protease inhibitors (dilution, 1:100; Beyotime Institute of Biotechnology, Nantong, China). Samples were centrifuged at $4^{\circ} \mathrm{C}$ for $20 \mathrm{~min}$ at $800 \mathrm{x} \mathrm{g}$. Supernatants were recovered and total protein was quantified using the aforementioned BCA protein assay kit. Equal amounts of protein were loaded and separated on $10 \%$ SDS-polyacrylamide gels and transferred to PVDF membranes. The membranes were blocked for $1 \mathrm{~h}$ at room temperature with $5 \%$ milk in TBS supplemented with $0.05 \%$ Tween-20 (TBST), incubated for $1 \mathrm{~h}$ with the corresponding primary antibody [anti-PI3K p85, dilution, 1:5,000; anti-phosphorylated (p)-AKT1, dilution, 1:2,000; anti-total (t)-AKT1, dilution, 1:1,000; anti-p-mTOR, dilution, 1:2,000; anti-t-mTOR, dilution, 1:5,000; and anti-GAPDH, dilution 1:5,000], washed three times with TBST, incubated with horseradish peroxidase-conjugated goat anti-rabbit IgG (dilution, $1: 20,000 ; 40 \mathrm{~min}$ at $37^{\circ} \mathrm{C}$ ), washed three times with TBST and visualized using the aforementioned ECL reagent. GAPDH served as an internal loading control. 


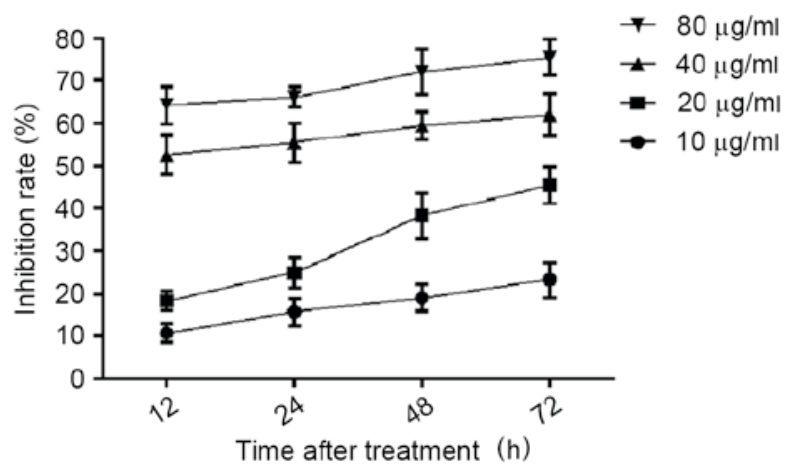

Figure 1. Effect of CDDP treatment on Ishikawa cell proliferation. Ishikawa cells were treated with 10,20,40 and $80 \mu \mathrm{g} / \mathrm{ml} \mathrm{CDDP}$ for 12,24, 48 and $72 \mathrm{~h}$. Cell proliferation assay was then performed using the CellTiter $96{ }^{\circledR}$ AQueous One Solution Cell Proliferation Assay kit, according to the manufacturer's protocol. CDDP; cisplatin.

Immunofluorescence microscopy. Ishikawa cells treated with $0,10,20,40$ or $80 \mu \mathrm{g} / \mathrm{ml}$ were grown on coverslips. After 0,12 or $24 \mathrm{~h}$, the cells were washed with PBS and fixed for 20 min with $4 \%$ paraformaldehyde at room temperature. The cells were then permeabilized for $5 \mathrm{~min}$ in $0.2 \%$ Triton X-100 and washed with PBS. In order to block non-specific background staining, the samples were incubated at $37^{\circ} \mathrm{C}$ in a solution containing 10\% normal goat serum (Boster Biological Technology) for $30 \mathrm{~min}$. Upon washing with PBS, the cells were incubated for $1 \mathrm{~h}$ at room temperature with primary rabbit polyclonal anti-LC3B antibody diluted in PBS supplemented with $1 \%$ bovine serum albumin (Boster Biological Technology). The cells were then rinsed with PBS and incubated with Alexa Fluor 488-conjugated donkey anti-rabbit $\mathrm{IgG}$ secondary antibodies for $60 \mathrm{~min}$ at room temperature. The nuclei were counterstained with DAPI for $5 \mathrm{~min}$ at room temperature. Upon washing with PBS, the stained cells were mounted with a fluorescent-mounting medium (Dako; Agilent Technologies, Inc., Santa Clara, CA, USA) and examined using a TCS SP2 AOBS confocal laser scanning microscope (Leica Microsystems GmbH, Wetzlar, Germany).

Statistical analysis. All results are presented as the mean \pm standard deviation, and were analysed using SPSS version 19.0 software (IBM SPSS, Armonk, NY, USA). A one-way analysis of variance was used to determine statistical significance. $\mathrm{P}<0.05$ was considered to indicate a statistically significant difference.

\section{Results}

Effect of CDDP treatment on Ishikawa cell proliferation. Prior to investigating the effect of CDDP on Ishikawa cell autophagy, the effect of CDDP on Ishikawa cell proliferation was evaluated, and a suitable treatment concentration and time were determined by the results of the cell proliferation assays. Ishikawa cells were treated with $10,20,40$ and $80 \mu \mathrm{g} / \mathrm{ml}$ CDDP for 12, 24, 48 and $72 \mathrm{~h}$. The cells were then harvested and subjected to cell proliferation assays. As presented in Fig. 1, the proliferation inhibition of Ishikawa cells treated with CDDP demonstrated dose- and time-dependent results. For the $10 \mu \mathrm{g} / \mathrm{ml} \mathrm{CDDP} \mathrm{treatment,} \mathrm{the} \mathrm{proliferation} \mathrm{inhibition}$

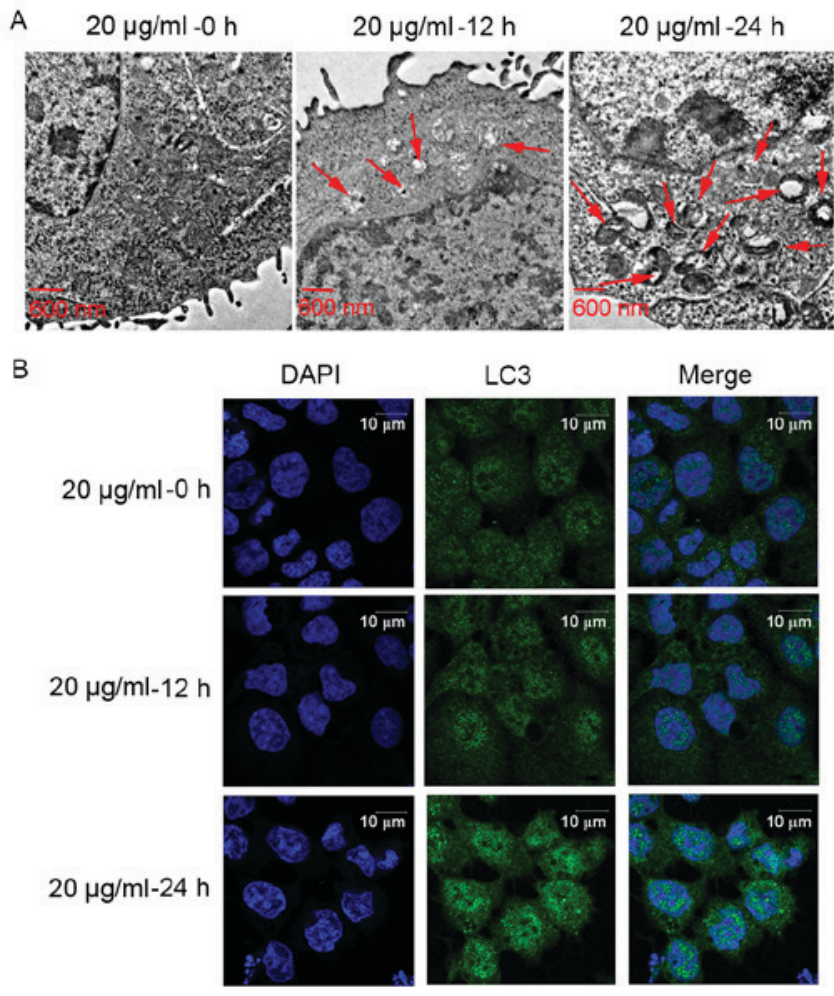

Figure 2. CDDP treatment promotes cell autophagy in Ishikawa cells (A) CDDP treatment enhanced the formation of intracellular autophagosomes in Ishikawa cells. Representative transmission electron microscope images from $20 \mu \mathrm{g} / \mathrm{ml}$ CDDP-treated cells for 0,12 and $24 \mathrm{~h}$ are presented (arrows indicate intracellular autophagosomes). (B) The expression level of the autophagy-associated gene LC3 was examined using immunofluorescence microscopy. CDDP; cisplatin; LC3, microtubule-associated protein 1 light chain $3 \alpha$.

rates were $18.27 \pm 2.25,24.88 \pm 3.58,38.27 \pm 5.34$ and $45.43 \pm 4.25$ following 12, 24, 48 and $72 \mathrm{~h}$ of treatment, respectively. For the $20 \mu \mathrm{g} / \mathrm{ml}$ CDDP treatment, the proliferation inhibition rate was $\leq 20 \%$ at all time-points. For the 40 and $80 \mu \mathrm{g} / \mathrm{ml}$ CDDP treatment, the proliferation inhibition rate was $<50 \%$ at all time points. Based on these results, $20 \mu \mathrm{g} / \mathrm{ml} \mathrm{CDDP} \mathrm{treat-}$ ment for 12 or $24 \mathrm{~h}$ was selected as the concentration and time periods for the subsequent assays.

Promotion of cell autophagy induced by CDDP treatment in Ishikawa cells. To detect the effect of CDDP on Ishikawa cell autophagy, the formation of autophagosomes was observed using a transmission electron microscope. As presented in Fig. 2A, the number of intracellular autophagosomes following $20 \mu \mathrm{g} / \mathrm{ml}$ CDDP treatment for $12 \mathrm{~h}$ increased compared with that of the control group (no treatment). In addition, the number of intracellular autophagosomes following $20 \mu \mathrm{g} / \mathrm{ml} \mathrm{CDDP}$ treatment for $24 \mathrm{~h}$ was higher than that following $20 \mu \mathrm{g} / \mathrm{ml}$ CDDP treatment for $12 \mathrm{~h}$. Furthermore, in order to determine the effect of CDDP treatment on cell autophagy, the expression level of the autophagy-related gene (ATG) LC3 (17), was examined using immunofluorescence microscopy. The LC3 protein expression levels following $20 \mu \mathrm{g} / \mathrm{ml}$ CDDP treatment for $12 \mathrm{~h}$ were increased compared with those of the group that did not receive treatment. The LC3 protein expression level following $20 \mu \mathrm{g} / \mathrm{ml} \mathrm{CDDP}$ treatment for $24 \mathrm{~h}$ was higher than that following $20 \mu \mathrm{g} / \mathrm{ml}$ CDDP 


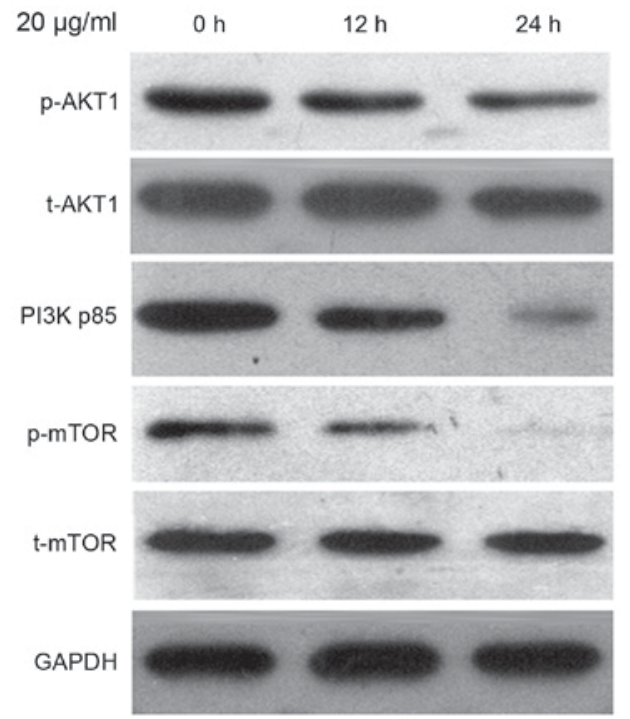

Figure 3. The protein expression level of PI3K p85, p-AKT1,t-AKT1, p-mTOR and t-mTOR were detected using western blot analysis. Ishikawa cells were treated with $20 \mu \mathrm{g} / \mathrm{ml}$ CDDP for 12 and $24 \mathrm{~h}$, followed by harvesting for western blot analysis. PI3K, phosphoinositide 3-kinase; p-, phosphorylated; $\mathrm{t}-$, total; AKT, protein kinase B; mTOR, mammalian target of rapamycin; CDDP, cisplatin.

treatment for $12 \mathrm{~h}$. In brief, CDDP treatment may promote cell autophagy in a time-dependent manner in Ishikawa cells. Based on these results, $20 \mu \mathrm{g} / \mathrm{ml}$ CDDP treatment for $24 \mathrm{~h}$ was selected as the concentration and time to be used for the following assays.

Inactivation of the PI3K/AKT/mTOR signalling pathway by $C D D P$ treatment. To investigate the mechanism underlying the effect of CDDP treatment on autophagy in Ishikawa cells, the protein expression level of PI3K p85, p-AKT1, t-AKT1, p-mTOR and t-mTOR were evaluated by the western blot analysis. As presented in Fig. 3, the t-AKT1 and t-mTOR expression levels remained constant; however, the expression levels of p-Akt and p-mTOR were reduced in cells treated with $20 \mu \mathrm{g} / \mathrm{ml} \mathrm{CDDP}$ for $24 \mathrm{~h}$. Reduction in the expression level of PI3K p85 was also observed.

IGF-1 co-treatment reverses the effect of CDDP on cell autophagy in Ishikawa cells. To further evaluate the effect of CDDP on cell autophagy in Ishikawa cells via the PI3K/AKT/mTOR signalling pathway, the cells were co-treated with a PI3K activator, IGF-1, at $100 \mathrm{ng} / \mathrm{ml}$. As presented in Fig. 4, the number of intracellular autophagosomes following treatment with $20 \mu \mathrm{g} / \mathrm{ml} \mathrm{CDDP}$ and IGF-1 co-treatment for $24 \mathrm{~h}$ was decreased compared with that in the $20 \mu \mathrm{g} / \mathrm{ml} \mathrm{CDDP}$ treatment group. However, the number of intracellular autophagosomes following $20 \mu \mathrm{g} / \mathrm{ml}$ CDDP and IGF-1 co-treatment was higher than that in the cells treated with DMSO alone. Furthermore, the expression level of the ATG LC3 was examined using immunofluorescence microscopy. The LC3 protein expression levels following $20 \mu \mathrm{g} / \mathrm{ml}$ CDDP and IGF-1 co-treatment were decreased compared with those in the $20 \mu \mathrm{g} / \mathrm{ml}$ CDDP treatment group. However, the LC3 protein expression level following $20 \mu \mathrm{g} / \mathrm{ml}$ CDDP and IGF-1 co-treatment was higher than that in the DMSO-only
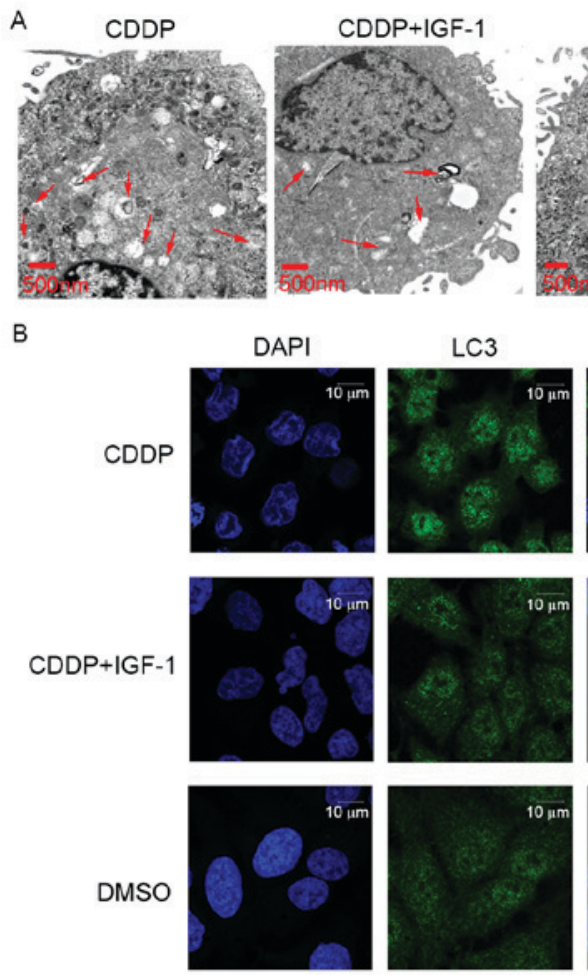

DMSO

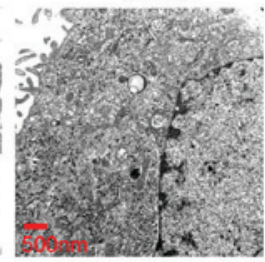

Merge
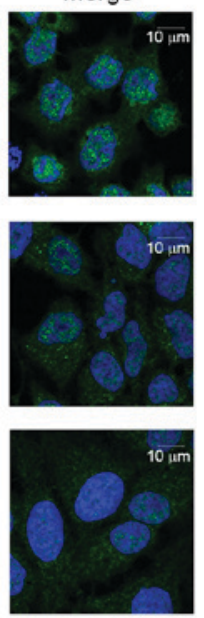

Figure 4. IGF-1 co-treatment reverses the effect of CDDP on cell autophagy in Ishikawa cells. (A) CDDP and IGF-1 co-treatment reduced the formation of intracellular autophagosomes in Ishikawa cells. Representative transmission electron microscope images from the $20 \mu \mathrm{g} / \mathrm{ml}$ CDDP treatment group $20 \mu \mathrm{g} / \mathrm{ml} \mathrm{CDDP}$ and IGF-1 co-treatment group and the control cell group are presented (arrows indicate intracellular autophagosomes). (B) The expression level of the autophagy-associated gene LC3 was examined using immunofluorescence microscopy. CDDP, cisplatin; IGF-1, insulin-like growth factor 1 ; LC3, microtubule-associated protein 1 light chain $3 \alpha$.

group. In brief, IGF-1 co-treatment may partially reverse the effect of CDDP on cell autophagy in Ishikawa cells.

\section{Discussion}

CDDP is a highly effective chemotherapeutic agent used for the treatment of human solid tumours, including endometrial cancer (18). However, the cytotoxicity induced by CDDP is an important obstacle in its utility and therapeutic profile. CDDP and other platinum-based compounds are considered as cytotoxic drugs that kill cancer cells by damaging the DNA, inhibiting DNA synthesis and mitosis, and inducing apoptotic cell death (19). CDDP chemotherapy is also associated with substantial side effects, including hepatotoxic, nephrotoxic, cardiotoxic, neurotoxic and/or hematotoxic damage (19). The molecular mechanism underlying the cytotoxic effects induced by CDDP was widely discussed in previous studies, and numerous molecular mechanisms are explained, including the induction of oxidative stress, which is characterized by reactive oxygen species production and lipid peroxidation; induction of p53 signalling and cell cycle arrest; downregulation of proto-oncogenes and anti-apoptotic proteins; and activation of intrinsic and extrinsic pathways of apoptosis (19-22). In previous studies, autophagy, a highly regulated self-degradation process of eukaryotic cells, was identified as one of the molecular mechanisms underlying CDDP cytotoxicity in certain types 
of cancer cells and in normal cells $(10,23)$. Autophagy is a context-dependent tumour-suppressing mechanism that can also promote tumour cell survival under stress conditions and treatment resistance (24). The present study aimed to discuss the association between autophagy and CDDP in endometrial cancer. Therefore, the current results will aid in the explanation of molecular mechanisms underlying CDDP cytotoxicity in endometrial cancer.

The dynamic process of autophagy involves membrane formation and fusion, including autophagosome formation, autophagosome-lysosome fusion and the degradation of intra-autophagosomal contents by lysosomal hydrolases (25). The present study used transmission electron microscopy to detect the formation of intracellular autophagosomes in Ishikawa cells following CDDP treatment. The results revealed that CDDP treatment may increase the number of intracellular autophagosomes in a time-dependent manner in Ishikawa cells. To further determine the effect of CDDP treatment on cell autophagy, the expression level of the ATG LC3 (15) was examined using immunofluorescence microscopy. The results demonstrated that CDDP treatment may upregulate LC3 protein expression level. Together, these results revealed that CDDP treatment promoted cell autophagy in the Ishikawa endometrial cancer cells. The results of the present study are in accord with previous studies $(10,12)$. In Huh7 and HepG2 hepatocellular carcinoma cells, CDDP treatment activated autophagy (10), and in human lung adenocarcinoma cells, LC3-II was increased in the A549/DDP CDDP-resistant cells compared with that in A549 cells (12).

$\mathrm{PI} 3 \mathrm{~K} / \mathrm{AKT} / \mathrm{mTOR}$ signalling pathway activation is heavily implicated in endometrial cancer pathogenesis (14). The results of the present study revealed that CDDP treatment may inactivate the PI3K/AKT/mTOR signalling pathway. In addition co-treatment with a PI3K activator, IGF-1, may reverse the effect of CDDP on cell autophagy in Ishikawa cells. The association between CDDP and the PI3K/AKT/mTOR signalling pathway was also discussed in other cells. In non-small cell lung cancer cells, platycodin-D induced autophagy in NCI-H460 and A549 cells via inhibition of the PI3K/AKT/mTOR signalling pathway (26), while in human cervical cancer cells, licochalcone A induced autophagy via inactivation of the PI3K/AKT/mTOR signalling pathway (27). Based on these results, the present study hypothesized that CDDP may regulate cell autophagy in the Ishikawa endometrial cancer cells by the PI3K/AKT/mTOR signalling pathway.

\section{Acknowledgements}

The present study was supported by the General Guidance Project of Guangzhou City Health Bureau (grant no. 20151A010106).

\section{References}

1. Jemal A, Bray F, Center MM, Ferlay J, Ward E and Forman D: Global cancer statistics. CA Cancer J Clin 61: 69-90, 2011.

2. Magrina JF, Mutone NF, Weaver AL, Magtibay PM, Fowler RS and Cornella JL: Laparoscopic lymphadenectomy and vaginal or laparoscopic hysterectomy with bilateral salpingo-oophorectomy for endometrial cancer: Morbidity and survival. Am J Obstet Gynecol 181: 376-381, 1999.

3. National Cancer Institute: Cancer Stat Facts: Endometrial Cancer, 2015.
4. Klionsky DJ and Emr SD: Autophagy as a regulated pathway of cellular degradation. Science 290: 1717-1721, 2000.

5. White E and DiPaola RS: The double-edged sword of autophagy modulation in cancer. Clin Cancer Res 15: 5308-5316, 2009.

6. Du F, Feng Y, Fang J and Yang M: MicroRNA-143 enhances chemosensitivity of Quercetin through autophagy inhibition via target GABARAPL1 in gastric cancer cells. Biomed Pharmacother 74: 169-177, 2015.

7. Liu YP, Dong FX, Chai X, Zhu S, Zhang BL and Gao DS: Role of autophagy in capsaicin-induced apoptosis in U251 Glioma Cells. Cell Mol Neurobiol 36: 737-743, 2016

8. Nazim UM and Park SY: Genistein enhances TRAIL-induced cancer cell death via inactivation of autophagic flux. Oncol Rep 34: 2692-2698, 2015.

9. Zhang Y, Jiang F, Bao W, Zhang H, He X, Wang H and Wan X: SOX17 increases the cisplatin sensitivity of an endometrial cancer cell line. Cancer Cell Int 16: 29, 2016.

10. Xu N, Zhang J, Shen C, Luo Y, Xia L, Xue F and Xia Q: Cisplatin-induced downregulation of miR-199a-5p increases drug resistance by activating autophagy in HCC cell. Biochem Biophys Res Commun 423: 826-831, 2012.

11. Kang R, Wang ZH, Wang BQ, Zhang CM, Gao W, Feng Y, Bai T, Zhang HL, Huang-Pu $\mathrm{H}$ and Wen SX: Inhibition of autophagy-potentiated chemosensitivity to cisplatin in laryngeal cancer Hep-2 cells. Am J Otolaryngol 33: 678-684, 2012.

12. Ren JH, He WS, Nong L, Zhu QY, Hu K, Zhang RG, Huang LL, Zhu F and Wu G: Acquired cisplatin resistance in human lung adenocarcinoma cells is associated with enhanced autophagy. Cancer Biother Radiopharm 25: 75-80, 2010.

13. Chen J, Zhao KN, Li R, Shao R and Chen C: Activation of $\mathrm{PI} 3 \mathrm{~K} / \mathrm{Akt} / \mathrm{mTOR}$ pathway and dual inhibitors of PI3K and mTOR in endometrial cancer. Curr Med Chem 21: 3070-3080, 2014.

14. Slomovitz BM and Coleman RL: The PI3K/AKT/mTOR pathway as a therapeutic target in endometrial cancer. Clin Cancer Res 18: 5856-5864, 2012.

15. Lum JJ, Bauer DE, Kong M, Harris MH, Li C, Lindsten T and Thompson CB: Growth factor regulation of autophagy and cell survival in the absence of apoptosis. Cell 120: 237-248, 2005.

16. Levine B and Kroemer G: Autophagy in the pathogenesis of disease. Cell 132: 27-42, 2008.

17. Chen Y, Li X, Wu X, He C, Guo L, Zhang S, Xiao Y, Guo W and Tan B: Autophagy-related proteins LC3 and Beclin-1 impact the efficacy of chemoradiation on esophageal squamous cell carcinoma. Pathol Res Pract 209: 562-567, 2013

18. Youn CK, Kim J,Park JH, Do NY and Cho SI: Role of autophagy in cisplatin-induced ototoxicity. Int J Pediatr Otorhinolaryngol 79: 1814-1819, 2015.

19. Dasari S and Tchounwou PB: Cisplatin in cancer therapy: Molecular mechanisms of action. Eur J Pharmacol 740: 364-378, 2014.

20. Jiang Y, Guo C, Vasko MR and Kelley MR: Implications of apurinic/apyrimidinic endonuclease in reactive oxygen signaling response after cisplatin treatment of dorsal root ganglion neurons. Cancer Res 68: 6425-6434, 2008.

21. DeHaan RD, Yazlovitskaya EM and Persons DL: Regulation of p53 target gene expression by cisplatin-induced extracellular signal-regulated kinase. Cancer Chemother Pharmacol 48: 383-388, 2001

22. Zhu H, Luo H, Zhang W, Shen Z, Hu X and Zhu X: Molecular mechanisms of cisplatin resistance in cervical cancer. Drug Des Devel Ther 10: 1885-1895, 2016.

23. Kaushal GP, Kaushal V, Herzog C and Yang C: Autophagy delays apoptosis inrenal tubular epithelial cells in cisplatin cytotoxicity. Autophagy 4: 710-712, 2008.

24. Kubisch J, Turei D, Földvári-Nagy L, Dunai ZA, Zsákai L, Varga M, Vellai T, Csermely $\mathrm{P}$ and Korcsmáros T: Complex regulation of autophagy in cancer-integrated approaches to discover the networks that hold a double-edged sword. Semin Cancer Biol 23: 252-261, 2013.

25. Tanida I: Autophagosome formation and molecular mechanism of autophagy. Antioxid Redox Signal 14: 2201-2214, 2011.

26. Zhao R, Chen M, Jiang Z, Zhao F, Xi B, Zhang X, Fu H and Zhou K: Platycodin-D induced autophagy in non-small cell lung cancer cells via PI3K/Akt/mTOR and MAPK Signaling Pathways. J Cancer 6: 623-631, 2015.

27. Tsai JP, Lee CH, Ying TH, Lin CL, Hsueh JT and Hsieh YH: Licochalcone A induces autophagy through PI3K/Akt/mTOR inactivation and autophagy suppression enhances Licochalcone A-induced apoptosis of human cervical cancer cells. Oncotarget 6: 28851-28866, 2015. 